\title{
O que pode o ensino de filosofia na BNCC?
}

\author{
What can teaching of philosophy does at BNCC?
}

\author{
André Luis La Salvia \\ Professor doutor da Universidade Federal do ABC, São Bernardo do Campo, SP, \\ Brasil. \\ la.salvia@ufabc.edu.br - https://orcid.org/0000-0002-1111-5052
}

\author{
Osvaldo Cunha Neto \\ Professor doutor do Instituto Federal de Rondônia, Vilhena, RO, Brasil \\ osvaldocunhaneto@gmail.com - https://orcid.org/0000-0002-5670-8062
}

Recebido em 25 de agosto de 2021

Aprovado em 17 de outubro de 2021

Publicado em 30 de dezembro de 2021

RESUMO: O presente artigo apresenta uma reflexão sobre as possibilidades para o ensino de filosofia como disciplina na atual Base Nacional Comum Curricular (BNCC). O objetivo é analisar as competências e habilidades da base para extrair conceitos e noções que necessariamente demandam uma atuação específica da filosofia, como disciplina curricular obrigatória. Através do desenvolvimento da discussão, é demonstrado o quanto a filosofia é uma disciplina estrutural e necessária ao desenvolvimento de certas competências gerais e competências e habilidades das Ciências Humanas e Sociais Aplicadas. Além disso, o material aqui reunido visa embasar, conceitual e legalmente, a necessidade estratégica da filosofia no currículo para legitimar a pretensão pedagógica da BNCC, que professa uma educação que conjugue conhecimentos, valores e posicionamentos sociais e éticos.

Palavras-chave: Ensino de filosofia; Currículo; BNCC; competências; habilidades; filosofia.

ABSTRACT: This article presents a reflection on the possibilities for teaching philosophy as a discipline in the current National Common Curriculum Base (BNCC, in portuguese). The objective is to analyze the competences and skills of the base to extract concepts and notions that necessarily demand a specific performance of philosophy, as a mandatory curricular subject. Through the development of the discussion, it is demonstrated how philosophy is a structural discipline and necessary for the development of certain general competences and competences and skills of the Applied Human and Social Sciences. In addition, the material gathered here aims to ground, conceptually and legally, the strategic need for philosophy in the curriculum to legitimize the pedagogical intention of BNCC, which professes an education that combines knowledge, values and ethical social positions.

Keywords: Teaching of philosophy; BNCC; competences; skills; philosophy. 


\section{Introdução}

Antes de assumirmos que há motivos para lamentarmos as mudanças promovidas pelas Bases Nacionais Curriculares Comuns (Brasil, 2018), analisaremos, nos documentos oficiais que tratam do assunto, as efetivas mudanças propostas e os impactos no aumento, ou diminuição, do papel da disciplina filosofia na formação básica dos estudantes.

O objetivo foi pensar o ensino de filosofia na nova legislação sobre o ensino médio e, como a presença da filosofia no currículo da educação básica possui uma história intermitente, muitos sentiram que ela foi mais uma vez ameaçada de desaparecer, ou escanteada para uma posição secundária. Será que podemos pensar de outro modo? O que pode a filosofia nessa BNCC?

A tarefa que se propôs esse artigo parecia ingrata. Como a filosofia foi inserida na área de Ciências Humanas e Sociais Aplicadas, seria preciso refletir em que momentos o ensino de filosofia aparece no documento e propor algumas rotinas curriculares que poderiam ser pensadas a partir dessa presença.

O tema é complexo e de múltiplas abordagens. Para contemplar fundamentações conceituais imprescindíveis a este debate, estão presentes em nosso texto, discussões sobre a concepção teórica da pedagogia das competências, seja para enaltecer suas características, como fazem Perrenoud (1999) e Delors (1999), seja para criticar como mercantilização da educação, como faz Laval (2018). Circulam, entre os pesquisadores sobre a BNNC, discussões sobre a concepção de educação como objetivos e direitos de aprendizagem, e ainda, discussões sobre se a filosofia deveria mesmo estar na área de Ciências Humanas e sociais. Optamos, ao não abordar essas questões, por uma análise do alcance da filosofia preconizado na letra da BNCC e, principalmente, se este alcance é, de fato, menor do que fora alcançado antes.

Em seu texto, a BNCC propõe que, além de garantir o acesso e permanência na educação, é necessário um patamar comum de aprendizagem (2018, p.8) e, assim, perguntamos: há lugar para o ensino de filosofia nesse patamar comum? Como proporcionar saberes filosóficos que vão além de habilidades para a 
flexibilidade, comunicação e resiliência para o mercado de trabalho, já que, para os defensores do tecnicismo e pragmatismo, a contribuição da filosofia deve-se limitarse em oferecer, quando muito, somente estas habilidades úteis aos estudantes?

\section{A filosofia na BNCC}

O texto da BNCC propõe diretrizes comuns para a construção de currículos diversos. Sendo assim não inclui, e nem exclui, as disciplinas no ensino médio, pois se limita a instituir competências e habilidades que serão materializadas em diversos currículos nas redes e escolas. Deixando, assim, para as redes públicas e as escolas as decisões acerca das disciplinas.

Uma das premissas deste texto é destacar algumas passagens nas quais a filosofia aparece como componente curricular da área de Ciências Humanas e Sociais Aplicadas. A primeira delas diz que "As áreas de Ciências da Natureza e suas Tecnologias (Biologia, Física e Química), Ciências Humanas e Sociais Aplicadas (História, Geografia, Sociologia e Filosofia)" (2018, p. 33). A área é entendida como sendo composta das respectivas disciplinas, não havendo muita margem para excluir uma delas do currículo. Há ainda dois outros trechos:

\footnotetext{
"No Ensino Médio, com a incorporação da Filosofia e da Sociologia, a área de Ciências Humanas e Sociais Aplicadas propõe o aprofundamento e a ampliação da base conceitual e dos modos de construção da argumentação e sistematização do raciocínio, operacionalizados com base em procedimentos analíticos e interpretativos". (2018, p. 472)

"A BNCC da área de Ciências Humanas e Sociais Aplicadas - integrada por Filosofia, Geografia, História e Sociologia - propõe a ampliação e o aprofundamento das aprendizagens essenciais desenvolvidas no Ensino Fundamental, sempre orientada para uma formação ética." (2018, p. 561)
}

Estas três passagens evidenciam, inequivocamente, que a Filosofia é contemplada enquanto componente curricular da área de Ciências Humanas e Sociais aplicadas. Sendo conferida a filosofia, inclusive, a função de ampliação e aprofundamento da base conceitual e construção de argumentos e raciocínios. Desse modo, dizer que a filosofia foi retirada do BNCC parece uma estratégia 
maquiavélica de quem almeja subtrair a disciplina a partir de uma leitura enviesada da lei, algo que jamais deveria ser propagado pelos envolvidos com seu ensino.

A sua presença é outra vez explicitada na base, quando esta cita as Diretrizes Curriculares Nacionais para o Ensino Médio (Resolução n. 3 de 21/11/2018), que diz em seu artigo 11, parágrafo 4 que:

"§ 40 Devem ser contemplados, sem prejuízo da integração e articulação das diferentes áreas do conhecimento, estudos e práticas de:

... VIII - sociologia e filosofia; $(2018$, p. 476)"

Embora a expressão "estudos e práticas" não oficializa, necessariamente, a obrigatoriedade da filosofia enquanto disciplina, tampouco suprime a necessidade de sua existência enquanto independente das demais. O referido parágrafo pode, inclusive, servir de embasamento aos defensores da necessidade da obrigatoriedade da filosofia, porque esta deve ser contemplada, "sem prejuízo da integração e articulação das diferentes áreas do conhecimento" e, assim, além de ter garantida a sua posição, a disciplina é apresentada como estratégica na articulação interdisciplinar com as demais disciplinas. Não teríamos uma supressão, mas, ao contrário, uma exaltação da filosofia e da sociologia.

Desse modo, apesar de a filosofia ser contemplada na BNCC, para garantir o seu efetivo oferecimento em forma de disciplina da grade curricular, é necessário um posicionamento efetivo e embasado. E parte desta legitimação consiste na produção de materiais didáticos que dialogam com a BNCC e que sejam oferecidos nos livros do Programa Nacional do Livro Didático (PNLD) para tratar das competências e habilidades que fazem menção a filosofia, que procuraremos destacar em seguida.

No PNLD, assim como nas escolas, a filosofia se fará presente na argumentação e explicitação dos conteúdos filosóficos que dialogam com as competências e habilidades propostas pelo BNCC, através da atuação efetiva dos professores de filosofia. O espaço do ensino de filosofia precisará ser constantemente criado e defendido por aqueles envolvidos em seu próprio ensino. Depois de anos de luta para a obrigatoriedade da disciplina, os docentes de filosofia terão que resistir e ver a luta pela sua presença ser travada constantemente, a cada 
criação de matrizes curriculares nos estados, a cada discussão curricular nas redes privadas de ensino e na criação dos livros do PNLD.

\title{
E quanto aos itinerários formativos?
}

O novo ensino médio e a BNCC preconizam em seus textos que pretendem levar a flexibilidade para os discentes do ensino médio, garantindo-lhes que possam optar por itinerários formativos a serem oferecidos pelas instituições de ensino. E a BNCC escolheu as próprias áreas (Linguagens, Matemática, Ciências da Natureza e Ciências Humanas e Sociais Aplicadas), acrescidas do ensino Técnico Profissional, para se configurarem como esses referidos itinerários.

A BNCC afirma ainda que a organização por áreas:

\begin{abstract}
não exclui necessariamente as disciplinas, com suas especificidades e saberes próprios historicamente construídos, mas, sim, implica o fortalecimento das relações entre elas e a sua contextualização para apreensão e intervenção na realidade, requerendo trabalho conjugado e cooperativo dos seus professores no planejamento e na execução dos planos de ensino (Parecer CNE/CP no 11/2009). (2018, p. 470)
\end{abstract}

A BNCC por mais de uma vez enaltece que os contextos locais, de cada escola, ou rede de ensino, devem definir o arranjo e, consequentemente, a oferta dessas áreas, delegando às redes estaduais e particulares a definição dos itinerários. A BNCC prescreve para cada uma dessas áreas uma série de competências e habilidades que são relativas a 1800 horas, ou $60 \%$ do ensino médio. Sendo que os restantes $40 \%$ devem ser decididos pelas redes, novamente prevalecendo o discurso de flexibilidade aos estudantes e contextualização na realidade escolar. Essa discussão gera uma problematização sobre a real capacidade de oferecimento aos estudantes de todos os itinerários e, consequentemente, se de fato vão poder escolher e, ainda, se estes estão preparados para isto. Neste artigo não entraremos nessa discussão, mesmo considerando-a importante.

Entendemos que essa divisão possibilita muitas leituras. Em uma delas, inclusive, pode-se esperar que um aluno tenha escolhido o itinerário formativo de 
Ciências Humanas e Sociais Aplicadas sinalizando com isso que deseja mais espaço curricular para as componentes da área, especificadas acima como História, Geografia, Filosofia e Sociologia. Ao sinalizar esse itinerário, este aluno estaria sinalizando que gostaria de aumentar a carga horária da área e, consequentemente, de filosofia. O que nos leva a uma impressão que seria possível aumentar os espaços de ensino de filosofia quando as escolas, ou redes de ensino, forem propor os currículos para quem escolhe o itinerário de Ciências Humanas. Desse modo, as escolas, ou redes de ensino, precisarão pensar a especificidade do currículo de filosofia para aqueles que optarem pelo itinerário de Ciências Humanas e Sociais. E, a depender do nosso engajamento, oxalá seja um dia necessário a nós, docentes da área, propor rotinas curriculares para um cenário de aumento de carga horária da filosofia.

Mais uma vez fica clara a necessidade de engajamento dos profissionais da área de filosofia para aumentar o seu campo de atuação. Como o conhecimento dos documentos oficiais demonstra, o espaço que será concedido aos professores de filosofia dependerá do quão necessário e conveniente ele se mostrar. Neste sentido, este artigo também deve ser entendido como um panfleto político cuja mensagem não precisa ser subliminar: ocupemos os espaços de debates!

Desse modo, no nosso entendimento, novamente prevalece a compreensão de que no novo ensino médio não há espaço garantido por lei para as disciplinas como normalmente entendemos, mas sim a construção necessária e constante de justificação de sua presença por parte dos protagonistas envolvidos no ensino de cada disciplina. No caso da filosofia essa necessidade se fará ainda mais premente por conta de seu passado oscilante enquanto disciplina obrigatória e o constante desprestígio pelo qual passa.

\section{Competências e habilidades e sua relação com a filosofia}

As mudanças no ensino médio e a criação da Base possuem como fundamento a concepção da pedagogia das competências. Já há algum tempo que os currículos escolares vêm sendo expressos por competências e habilidades, 
(desde, de pelos menos, a LDB de 1996 e da criação do Enem, em 1999). Monica Ribeiro da Silva, no seu artigo $A$ BNCC da reforma do ensino médio: o resgate de um empoeirado discurso (2018), aponta como a BNCC recupera o discurso das competências e habilidades dos documentos Parâmetros Curriculares Nacionais para o Ensino Médio (Brasil, 1999) e Parecer CNE/CEB 15/98 com a Resolução CNE/CEB 03/98. A autora afirma que

\begin{abstract}
A definição de competências como eixo de prescrições curriculares foi favorecida, no contexto da reforma curricular da década de 1990, em virtude de sua proximidade com a ideia de competição e de competitividade (SILVA, 2008). Esse discurso, agora revigorado, é retomado em meio às mesmas justificativas, de que é necessário adequar a escola a supostas e generalizáveis mudanças do "mundo do trabalho", associadas de modo mecânico e imediato a inovações de caráter tecnológico e organizacional (2018, p. 11)
\end{abstract}

Em ambos os casos, tanto no final dos anos 1990 como agora, a autora aponta que a pedagogia das competências possui um caráter de "formação administrada", instrumental, que não valoriza a dimensão histórico-cultural da formação humana. Isso é explícito nos documentos quando afirmam que "o novo paradigma emana da compreensão de que, cada vez mais, as competências desejáveis ao pleno desenvolvimento humano aproximam-se das necessárias à inserção no processo produtivo" (Brasil, 1999, p. 12).

Os Parâmetros citam como referência um relatório da UNESCO intitulado Educação, um tesouro a descobrir (1997), que tem Jacques Delors como um dos autores e nos quais são apresentadas as linhas mestras do paradigma das competências retiradas do universo do trabalho.

Em primeiro lugar, como dissemos, o progresso cientifico e tecnológico e a transformação dos processos de produção resultante da busca de uma maior competitividade fazem com que os saberes e as competências adquiridos, na formação inicial, tornem-se, rapidamente, obsoletos e exijam o desenvolvimento da formação profissional permanente. Esta dá resposta, em larga medida, a uma exigência de ordem econômica e faz com que a empresa se dote das competências necessárias para manter o nível de emprego e reforçar a sua competitividade. (1997, p. 104) 
Delors apresenta então os quatro pilares dessa nova pedagogia, são eles: aprender a conhecer, aprender a fazer, aprender a viver juntos e aprender a ser. Pilares esses adotados integralmente nos Parâmetros, de 1999, e que expressam as capacidades de aprender permanentemente e a flexibilidade para adequar-se às mudanças.

Outro autor que reflete sobre a pedagogia das competências e que possui ampla divulgação no Brasil é Philipe Perrenoud. Na sua obra Construir as competências desde a escola (1999), o autor fala da pedagogia das competências a partir do mundo do trabalho:

como o mundo do trabalho apropriou-se da noção de competência, a escola estaria seguindo seus passos, sob o pretexto de modernizar-se e de inserirse na corrente dos valores da economia de mercado, como gestão dos recursos humanos, busca da qualidade total, valorização da excelência, exigência de uma maior mobilidade dos trabalhadores e da organização do trabalho (p. 12)

Esse fator não era exclusivo para a ascensão do discurso das competências. O fator complementar é que a pedagogia das competências reanima um velho dilema, por ele descrito, entre os que querem transmitir a cultura e conhecimentos por si mesmos e os que querem ligá-los muito rapidamente a práticas sociais. Este debate denuncia uma "crise" nos sistemas educativos no sentido de que os orçamentos aumentaram, mas os níveis de formação não. E a competência poderia ser uma forma de sair dessa crise, uma vez que

a inovação consistiria não em fazer emergir a ideia de competência na escola, mas sim em aceitar "todo programa orientado pelo desenvolvimento de competências, as quais tem um poder de gerenciamento sobre os conhecimentos disciplinares" (Tardif, 1996, p. 45). (1999, p. 15)

Complementar a essa ideia temos que destacar que Perrenoud define competência como "uma capacidade de agir eficazmente em um determinado tipo de situação, apoiada em conhecimentos, mas sem limitar-se a eles” (1999, p. 7), sendo que concebe a "inteligência como capacidade multiforme de adaptação às diferenças e às mudanças" (1999, p. 15) e que a "abordagem por competências não 
rejeita nem os conteúdos, nem as disciplinas, mas sim acentua sua implementação" (1999, p. 15) tendo como pano de fundo um mundo no qual "das fronteiras, das tecnologias, dos estilos de vida requer uma flexibilidade e criatividade crescentes dos seres humanos, no trabalho e na cidade" (1999, p.15). Essas definições e articulações aparecem todas na BNCC.

O que a BNCC apresenta como novidade é a delimitação de dez competências gerais da educação e também a especificação de competências para cada etapa do ensino (infantil, fundamental e médio) e para cada área.

De certa forma isso já havia sido proposto em outros documentos oficiais e, no caso da filosofia, temos as Orientações Curriculares para o Ensino Médio, Ciências Humanas e suas tecnologias (2006). Mas este documento, diferente da BNCC, defende explicitamente a filosofia como disciplina no nível médio e apresenta competências e habilidades filosóficas (elaboradas a partir das Diretrizes Curriculares aos Cursos de Graduação em Filosofia e pela Portaria INEP $n^{0} 171$, de 24 de agosto de 2005, que instituiu o Exame Nacional de Desempenho dos Estudantes (Enade) de Filosofia), são elas:

$\left.1^{\circ}\right)$ Representação e comunicação:

- ler textos filosóficos de modo significativo;

- ler de modo filosófico textos de diferentes estruturas e registros;

- elaborar por escrito o que foi apropriado de modo reflexivo;

- debater, tomando uma posição, defendendo-a argumentativamente e mudando de posição em face de argumentos mais consistentes.

$2^{\circ}$ ) Investigação e compreensão:

- articular conhecimentos filosóficos e diferentes conteúdos e modos discursivos nas ciências naturais e humanas, nas artes e em outras produções culturais.

$3^{\circ}$ ) Contextualização sociocultural:

- contextualizar conhecimentos filosóficos, tanto no plano de sua origem específica quanto em outros planos: o pessoal-biográfico; o entorno sóciopolítico, histórico e cultural; o horizonte da sociedade científico-tecnológica (p. 33-34)

Temos três grandes competências filosóficas destacadas e com elas habilidades específicas. Veremos, entretanto, que elas não são retomadas na BNCC. Não obstante, é imprescindível destacar que as Orientações Curriculares para o Ensino Médio, Ciências Humanas e suas tecnologias (2006) continuam válidas e ainda podem embasar o trabalho com ensino de filosofia. 
Por outro lado, a pedagogia das competências é alvo de uma contundente crítica por fazer parte de um processo maior de mercadorização da educação, como propõe Cristian Laval (2019). A mercadorização da educação é um fenômeno mundial e consiste basicamente em tratar a educação como um bem privado e não mais um bem comum. Enquanto bem privado, é um investimento e está ligado a meritocracia e ganhos pessoais não sendo mais uma forma de transmitir cultura de modo igualitário. E a pedagogia das competências é apenas um dos aspectos desse paradigma.

Laval destaca que com a escola neoliberal há a passagem de um formato humanista para a emancipação intelectual e autonomia, na qual o trabalho não é a única ocupação da vida, para uma formação de assalariado qualificado, que tem sua própria formação como um ativo no qual investe, tendo o trabalho invadido todas as dimensões da vida. Nesse cenário, as competências não são para a vida, mas úteis profissionalmente, como afirma Laval "a competência é aquilo por que o indivíduo é útil na organização produtiva" (2019, p. 77).

A principal competência é 'aprender a aprender' e assim outras características podem ser desenvolvidas nos alunos da educação básica visando o seu futuro profissional, como: desempenho; competitividade; produtividade econômica; qualidade de trabalho; flexibilidade; autodisciplina. Nesse sentido, Laval aponta que "definida como característica individual, a categoria de competência faz parte da estratégia de individualização das novas políticas de gestão dos recursos humanos" (2019, p. 78).

O contraponto crítico denuncia, então, as competências como uma expressão de uma escola neoliberal que vê a educação como um bem de investimento privado e não como um meio de democratizar a cultura, de igualdade política e justiça social.

\section{As competências gerais e da área e sua relação com a filosofia}

Na seção anterior apresentamos, em linhas gerais, a problemática acerca da noção de pedagogia das competências. A BNCC, por sua vez, define competência como: 
como a mobilização de conhecimentos (conceitos e procedimentos), habilidades (práticas, cognitivas e socioemocionais), atitudes e valores para resolver demandas complexas da vida cotidiana, do pleno exercício da cidadania e do mundo do trabalho. $(2018$, p. 8$)$

Na BNCC são apresentadas dez competências gerais para o Ensino médio e depois seis competências específicas para as ciências humanas e sociais aplicadas.

No caso específico da filosofia, há uma diferença fundamental em relação às Orientações de 2006, pois lá se propõe competências filosóficas e aqui são competências gerais e competências e habilidades específicas da área de Ciências Humanas e Sociais Aplicadas. Desse modo, a principal diferença com relação às Orientações é que elas são explícitas em destacar a importância do ensino de filosofia como disciplina para o desenvolvimento das competências e, no caso da BNCC, teremos que fazer um trabalho de extração dessa importância.

Eis o quadro como apresentado pelo documento: 


\section{Quadro 01 - Competências Gerais da Educação Básica}

1. Valorizar e utilizar os conhecimentos historicamente construídos sobre o mundo físico, social, cultural e digital para entender e explicar a realidade, continuar aprendendo e colaborar para a construção de uma sociedade justa, democrática e inclusiva.

2. Exercitar a curiosidade intelectual e recorrer à abordagem própria das ciências, incluindo a investigação, a reflexão, a análise crítica, a imaginação e a criatividade, para investigar causas, elaborar e testar hipóteses, formular e resolver problemas e criar soluções (inclusive tecnológicas) com base nos conhecimentos das diferentes áreas.

3. Valorizar e fruir as diversas manifestações artísticas e culturais, das locais às mundiais, e também participar de práticas diversificadas da produção artístico-cultural.

4. Utilizar diferentes linguagens - verbal (oral ou visual-motora, como Libras, e escrita), corporal, visual, sonora e digital -, bem como conhecimentos das linguagens artística, matemática e científica, para se expressar e partilhar informações, experiências, ideias e sentimentos em diferentes contextos e produzir sentidos que levem ao entendimento mútuo.

5. Compreender, utilizar e criar tecnologias digitais de informação e comunicação de forma crítica, significativa, reflexiva e ética nas diversas práticas sociais (incluindo as escolares) para se comunicar, acessar e disseminar informações, produzir conhecimentos, resolver problemas e exercer protagonismo e autoria na vida pessoal e coletiva.

6. Valorizar a diversidade de saberes e vivências culturais e apropriar-se de conhecimentos e experiências que the possibilitem entender as relações próprias do mundo do trabalho e fazer escolhas alinhadas ao exercício da cidadania e ao seu projeto de vida, com liberdade, autonomia, consciência crítica e responsabilidade.

7. Argumentar com base em fatos, dados e informações confiáveis, para formular, negociar e defender ideias, pontos de vista e decisões comuns que respeitem e promovam os direitos humanos, a consciência socioambiental e o consumo responsável em âmbito local, regional e global, com posicionamento ético em relação ao cuidado de si mesmo, dos outros e do planeta.

8. Conhecer-se, apreciar-se e cuidar de sua saúde física e emocional, compreendendo-se na diversidade humana e reconhecendo suas emoções e as dos outros, com autocrítica e capacidade para lidar com elas.

9. Exercitar a empatia, o diálogo, a resolução de conflitos e a cooperação, fazendo-se respeitar e promovendo o respeito ao outro e aos direitos humanos, com acolhimento e valorização da diversidade de indivíduos e de grupos sociais, seus saberes, identidades, culturas e potencialidades, sem preconceitos de qualquer natureza.

10. Agir pessoal e coletivamente com autonomia, responsabilidade, flexibilidade, resiliência e determinação, tomando decisões com base em princípios éticos, democráticos, inclusivos, sustentáveis e solidários.

Fonte: BRASIL. Base Nacional Comum Curricular: Educação é a base - Ensino Médio. 2018. P. 9-10

Se nas Orientações temos três grupos (representação e comunicação; investigação e compreensão; contextualização sociocultural). Aqui, diante de tal 
lista, criamos duas constantes para análise: aquelas competências ligadas a procedimentos intelectuais e epistemológicos e aquelas ligadas a valores e comportamentos. Desse modo, propomos a divisão em:

- Procedimentos ou metodologias - utilizar conhecimentos históricos; abordagem cientifica; exercitar a curiosidade intelectual; elaborar e testar hipóteses; usar diferentes linguagens, expressar pensamentos; lidar com novas tecnologias; argumentação.

- Valores e comportamento - construção de sociedade justa; criatividade; valorizar diversidade cultural e artística; entendimento mútuo; valorizar diversidade cultural, experiências para as escolhas e exercício da cidadania; direitos humanos, consciência socioambiental, posicionamento ético; autoconhecimento e autocuidado; diálogo; agir responsável e autônomo.

Há noções e conceitos caros ao ensino de filosofia nessas competências e, por isso, nosso esforço em legitimar a necessidade de ser oferecida como disciplina na grade curricular. É salutar destacar estes conceitos como a confirmação de que a BNCC pressupõe a filosofia como uma disciplina estratégica para sua proposta como um todo ser válida.

Seguem diferentes exemplos de como a filosofia incorpora competências estruturais da BNCC. Por exemplo: a curiosidade intelectual que muitas vezes é associada como a própria definição de filosofia, como sendo um espanto, ou admiração, pela realidade vista como intrigante e digna de investigação. Elaborar e testar hipóteses que é vista por muitos como uma das grandes contribuições da metodologia filosófica, incorporada por demais áreas. A argumentação, tida por muitos, como eminentemente filosófica, que, inclusive, possui uma área, a lógica, que estuda os processos argumentativos. O diálogo, por muitos também destacado como sendo uma característica da filosofia de expressão grega e que fundamenta boa parte da tradição filosófica ocidental. E, obviamente, a noção de expressão de pensamentos.

Todas essas competências podem ser desenvolvidas com os procedimentos curriculares propostos pelas Orientações de 2006, a saber, a leitura de textos 
filosóficos e leitura filosófica de textos de qualquer natureza. A elaboração de conteúdos de ensino de filosofia precisaria focar em instrumentos metodológicos que poderiam ser estimulados com uma diversidade de textos filosóficos e com linguagens variadas destacando a expressão de pensamento, bem como a sua contextualização histórica e o problema ao qual respondem.

Outro ponto que merece destaque é a enorme importância dada à discussão sobre valores e comportamentos que mobilizam outra área eminentemente filosófica, a discussão ética. Coloca-se como obrigação do ensino médio uma reflexão e um posicionamento éticos, citando o diálogo, respeito ao outro, autonomia, liberdade, cuidado de si e autoconhecimento. Todos eles conceitos propostos e amplamente discutidos em toda história da filosofia e que possuem nela não apenas a origem conceitual e fundamentos, como também o local próprio para o seu ensino. São aspectos que estão tão intimamente ligados ao ensino de filosofia e que possuem tamanho destaque na BNCC, que nos parece até mesmo um contrassenso querer desenvolver essas competências apenas como "estudos e práticas", ou em "projetos", e não como uma disciplina com carga horária regular.

\section{As categorias das ciências Humanas e Sociais aplicadas.}

Após as considerações gerais acima apresentadas sobre as competências gerais do ensino médio, vamos analisar brevemente um ponto importante da BNCC que são as chamadas "categorias" apresentadas no texto.

A área de Ciências Humanas e Sociais Aplicadas "deve tematizar e problematizar algumas categorias da área" (2018, p. 562). Para os autores, essas são categorias específicas com perspectivas e conceitos que devem ser desenvolvidos no ensino médio, sendo orientadoras tanto das competências e habilidades da área, quanto dos livros didáticos do PNLD e aqui está o principal motivo do destaque. As obras passarão a ser por áreas e temáticas, em torno dessas categorias. E nelas é possível perceber explicitamente menções ao papel formativo da filosofia: 
1) Tempo e Espaço, na qual se afirma que "O tempo é matéria de reflexão na Filosofia, na Física, na Matemática, na Biologia, na História, na Sociologia..." (p. 563);

2) Território e Fronteira (na qual não há explicitamente menção a filosofia).

3) Indivíduo, Natureza, Sociedade, Cultura e Ética, na qual afirma que:

$\mathrm{Na}$ busca da unidade, de uma natureza (physis), os primeiros pensadores gregos sistematizaram questões e se indagaram sobre as finalidades da existência, sobre o que era comum a todos os seres da mesma espécie, produzindo uma visão essencializada e metafísica sobre os seres humanos. (p. 565);

4) Política e Trabalho, na qual se destaca que:

A política está na origem do pensamento filosófico. Na Grécia Antiga, o exercício da argumentação e a discussão sobre os destinos das cidades e suas leis estimularam a retórica e a abstração como práticas necessárias para o debate em torno do bem comum. (p. 567)

e ainda,

A categoria trabalho, por sua vez, comporta diferentes dimensões filosófica, econômica, sociológica ou histórica: como virtude; como forma de produzir riqueza, de dominar e de transformar a natureza; como mercadoria; ou como forma de alienação. (p. 568).

No rol de categorias é explícita a contribuição curricular especifica que a filosofia pode e deve ter no ensino médio. Na primeira categoria, ressalta-se a questão do tempo como uma matéria de reflexão da filosofia, o que acarreta pensar em diferentes discussões ao longo da história e o quanto o conceito é fundamental para a teoria do conhecimento e para a metodologia do pensamento. A segunda categoria, apesar de não fazer menção explícita a filosofia, implicitamente temos a questão da formação das sociedades, a questão do respeito às diferenças, com questões ligadas aos preconceitos e xenofobia. A terceira categoria faz menção ao contexto dos filósofos pré-socráticos e sua pesquisa sobre a physis, o que nos remete a visão de conjunto da filosofia como origem dos demais ramos das 
especialidades dos saberes, o que confere à filosofia um destaque em quanto precursora do pensamento racionalizado. E, por fim, a associação entre o surgimento da pólis grega e o debate público e gestão da cidade, associando a própria noção de cidadania como indissociável da filosofia.

Mais uma vez, agora nas categorias, há menções explícitas à contribuição que o pensamento filosófico deve desenvolver no ensino médio e, no nosso entender, expressa a necessidade de horas aula de filosofia para serem desenvolvidas, assim como garantir seu espaço nas obras do PNLD.

\section{Competências e Habilidades da área e suas relações com a filosofia}

O mesmo procedimento de análise é feito, agora, com as competências específicas da área das Ciências Humanas e Sociais aplicadas. Teríamos o seguinte quadro:

Quadro 02 - Competências da área Ciências Humanas e Sociais Aplicadas

1. Analisar processos políticos, econômicos, sociais, ambientais e culturais nos âmbitos local, regional, nacional e mundial em diferentes tempos, a partir da pluralidade de procedimentos epistemológicos, científicos e tecnológicos, de modo a compreender e posicionar-se criticamente em relação a eles, considerando diferentes pontos de vista e tomando decisões baseadas em argumentos e fontes de natureza científica.

2. Analisar a formação de territórios e fronteiras em diferentes tempos e espaços, mediante a compreensão das relações de poder que determinam as territorialidades e o papel geopolítico dos Estados-nações.

3. Analisar e avaliar criticamente as relações de diferentes grupos, povos e sociedades com a natureza (produção, distribuição e consumo) e seus impactos econômicos e socioambientais, com vistas à proposição de alternativas que respeitem e promovam a consciência, a ética socioambiental e o consumo responsável em âmbito local, regional, nacional e global.

4. Analisar as relações de produção, capital e trabalho em diferentes territórios, contextos e culturas, discutindo o papel dessas relações na construção, consolidação e transformação das sociedades.

5. Identificar e combater as diversas formas de injustiça, preconceito e violência, adotando princípios éticos, democráticos, inclusivos e solidários, e respeitando os Direitos Humanos.

6. Participar do debate público de forma crítica, respeitando diferentes posições e fazendo escolhas alinhadas ao exercício da cidadania e ao seu projeto de vida, com liberdade, autonomia, consciência crítica e responsabilidade.

Fonte: BRASIL. Base Nacional Comum Curricular: Educaçao é a base - Ensino Médio. 2018. P. 570 
Aqui teríamos três constantes para as competências, seriam elas:

- Procedimentos, ou metodologias - procedimentos epistemológicos, científicos e tecnológicos, de modo a compreender e posicionar-se criticamente; análise crítica, debate público.

- Política e sociedade - fronteiras, relações de poder, Estado; produção, distribuição e consumo; relações sociais, capital, trabalho, transformação social; diferentes relações com a natureza.

- Valores e comportamento - justiça, preconceito, violência; Direitos Humanos; pluralidade de posições, exercício da cidadania, liberdade autonomia, consciência crítica e responsabilidade. A consciência, a ética socioambiental e o consumo responsável; cidadania.

Mais especificamente, são acrescidos aqui conceitos e noções ligados às dimensões política e da sociedade, além das dimensões de procedimentos e valores que já destacamos acima.

Além de todos os pontos destacados anteriormente como atributos conceituais e metodológicos essencialmente filosóficos (a saber, a proposição de problemas, elaboração de hipóteses, seleção evidências e argumentação através de textos filosóficos ou da leitura filosófica de textos de outras naturezas), temos agora, com a delimitação da área de Ciências Humanas, mais um ponto eminentemente filosófico que é o posicionamento crítico.

A noção de crítica é cara à filosofia, possuindo nela um aprofundamento da simples ideia de que a crítica é emitir uma opinião, ou juízo de valor. Na filosofia, geralmente a crítica é entendida como uma análise sistemática e essa contribuição precisa ser levada ao ensino médio.

Na especificação da área, surgem como campo conceitual noções ligadas a organização da sociedade e que, em filosofia, são geralmente estudadas pela filosofia política. Conceitos políticos básicos (Estado, poder, formas, sistemas e regimes de governo, soberania etc.) podem ser estudados na contextualização sociocultural, como propõe as Orientações de 2006. Ou seja, esses conceitos podem ser mobilizados a partir de problematizações, analises críticas, reflexões 
sobre os pressupostos, elaboração de hipóteses ou debate públicos em contextos que levem em conta o plano pessoal, o entorno sócio-político, histórico e cultural, bem como a sociedade científica e tecnológica. Aqui seria interessante, inclusive, problematizar a originalidade grega da filosofia, como o fazem autores como Renato Nogueira (2014) que apresenta a importante discussão das outras matrizes para a filosofia, bem como a presença da filosofia africana.

Destacamos novamente a presença dos conceitos ligados à dimensão ética, como: os fundamentos da ética, os conceitos de valores, liberdade, cooperação, autonomia, convivência democrática e solidariedade; Impasses ético-políticos ligados a questões tecnológicas e ambientais; Paternalismo, autoritarismo e populismo na política; Democracia, cidadania e direitos humanos; Justiça, igualdade e fraternidade.

Apesar do foco em conteúdos de ética e política, é inegável que o rol de conteúdos destacados acima é especificamente filosófico e, ao serem tratados transversalmente, ou dentro de outras disciplinas, perdem em compreensão, reflexão detalhada, visão de conjunto e construção de argumentos - que são atividades eminentemente filosóficas.

Cada uma das competências acima apresenta cinco ou seis habilidades descritas. Desse modo, passamos a destacar algumas dessas habilidades e podemos encontrar outras menções explícitas à filosofia, são elas:

\footnotetext{
(EM13CHS101) Identificar, analisar e comparar diferentes fontes e narrativas expressas em diversas linguagens, com vistas à compreensão de ideias filosóficas e de processos e eventos históricos, geográficos, políticos, econômicos, sociais, ambientais e culturais. (p. 572)

(EM13CHS103) Elaborar hipóteses, selecionar evidências e compor argumentos relativos a processos políticos, econômicos, sociais, ambientais, culturais e epistemológicos, com base na sistematização de dados e informações de diversas naturezas (expressões artísticas, textos filosóficos e sociológicos, documentos históricos e geográficos, gráficos, mapas, tabelas, tradições orais, entre outros). (p. 572)
}

São habilidades ligadas à competência um e, portanto, ligadas a procedimentos, ou metodologias. A compreensão de ideias filosóficas e o trabalho com argumentação nos textos filosóficos exigem, logicamente, o trabalho específico 
da aula de filosofia, com as metodologias e teorias do ensino de filosofia. Vale destacar, ainda, a menção explícita ao texto filosófico como dado básico a ser trabalhado em todos os seus pormenores.

A competência cinco, por sua vez, faz menção também explícita a reflexão e construção filosófica ao tratar dos princípios éticos imprescindíveis para a formação ética dos jovens. Desse modo, também se fazem imprescindíveis as aulas de filosofia para o desenvolvimento dessa competência.

(EM13CHS501). Analisar os fundamentos da ética em diferentes culturas, tempos e espaços, identificando processos que contribuem para a formação de sujeitos éticos que valorizem a liberdade, a cooperação, a autonomia, o empreendedorismo, a convivência democrática e a solidariedade.

(EM13CHS502) Analisar situações da vida cotidiana, estilos de vida, valores, condutas etc., desnaturalizando e problematizando formas de desigualdade, preconceito, intolerância e discriminação, e identificar ações que promovam os Direitos Humanos, a solidariedade e o respeito às diferenças e às liberdades individuais.

(EM13CHS503) Identificar diversas formas de violência (física, simbólica, psicológica etc.), suas principais vítimas, suas causas sociais, psicológicas e afetivas, seus significados e usos políticos, sociais e culturais, discutindo e avaliando mecanismos para combatê-las, com base em argumentos éticos.

(EM13CHS504) Analisar e avaliar os impasses ético-políticos decorrentes das transformações culturais, sociais, históricas, científicas e tecnológicas no mundo contemporâneo e seus desdobramentos nas atitudes e nos valores de indivíduos, grupos sociais, sociedades e culturas.

Além das competências e habilidades acima que explicitamente apresentam demandas da filosofia, acreditamos que existam outras nas quais a filosofia possa pleitear como sendo de sua responsabilidade desenvolver, ou seja, que estaria apta a propor rotinas curriculares sobre. Por exemplo: 
(EM13CHS202) Analisar e avaliar os impactos das tecnologias na estruturação e nas dinâmicas de grupos, povos e sociedades contemporâneos (fluxos populacionais, financeiros, de mercadorias, de informações, de valores éticos e culturais etc.), bem como suas interferências nas decisões políticas, sociais, ambientais, econômicas e culturais.

(EM13CHS303) Debater e avaliar o papel da indústria cultural e das culturas de massa no estímulo ao consumismo, seus impactos econômicos e socioambientais, com vistas à percepção crítica das necessidades criadas pelo consumo e à adoção de hábitos sustentáveis.

(EM13CHS602) Identificar e caracterizar a presença do paternalismo, do autoritarismo e do populismo na política, na sociedade e nas culturas brasileira e latino-americana, em períodos ditatoriais e democráticos, relacionando-os com as formas de organização e de articulação das sociedades em defesa da autonomia, da liberdade, do diálogo e da promoção da democracia, da cidadania e dos direitos humanos na sociedade atual.

(EM13CHS603) Analisar a formação de diferentes países, povos e nações e de suas experiências políticas e de exercício da cidadania, aplicando conceitos políticos básicos (Estado, poder, formas, sistemas e regimes de governo, soberania etc.).

(EM13CHS605) Analisar os princípios da declaração dos Direitos Humanos, recorrendo às noções de justiça, igualdade e fraternidade, identificar os progressos e entraves à concretização desses direitos nas diversas sociedades contemporâneas e promover ações concretas diante da desigualdade e das violações desses direitos em diferentes espaços de vivência, respeitando a identidade de cada grupo e de cada indivíduo.

De modo geral a BNCC apresenta explicitamente competências e habilidades que seriam típicas e, muitas vezes exclusivas, ao ensino de filosofia.

\section{O curioso caso do ensino religioso.}

No ensino fundamental, a BNCC apresenta uma área chamada ensino religioso, opcional para as escolas. E nela sugere que o seu ensino passou por diversas abordagens teórico-metodológicas, mas que neste momento o que se espera dela é "o reconhecimento da diversidade religiosa" (p. 435), através de uma perspectiva de

tratar os conhecimentos religiosos a partir de pressupostos éticos e científicos, sem privilégio de nenhuma crença ou convicção. Isso implica abordar esses conhecimentos com base nas diversas culturas e tradições religiosas, sem desconsiderar a existência de filosofias seculares de vida. (p. 436) 
O que nos pareceu curioso é a menção à filosofia de vida. Do que se tratam as filosofias seculares de vida? Qual a importância de uma reflexão sobre o divino a partir de uma perspectiva laica? Qual a contribuição que o professor de filosofia pode dar a esse assunto?

A BNCC afirma que, no âmbito da interculturalidade e da ética da alteridade, as filosofias de vida estão muito presentes no ensino religioso especificando duas competências ligadas a esta abordagem entre as seis elencadas, são elas:

1. Conhecer os aspectos estruturantes das diferentes tradições/movimentos religiosos e filosofias de vida, a partir de pressupostos científicos, filosóficos, estéticos e éticos.

2. Compreender, valorizar e respeitar as manifestações religiosas e filosofias de vida, suas experiências e saberes, em diferentes tempos, espaços e territórios. (p. 437)

Para dar conta dessas competências, a BNCC cria uma unidade temática que se chama Crenças religiosas e filosofias de vida na qual elenca habilidades que permeiam os quatro anos do ensino fundamental, como:

\footnotetext{
(EF07ER06) Identificar princípios éticos em diferentes tradições religiosas e filosofias de vida, discutindo como podem influenciar condutas pessoais e práticas sociais. (p. 455)

(EF08ER02) Analisar filosofias de vida, manifestações e tradições religiosas destacando seus princípios éticos. (p. 457)

(EF08ER04) Discutir como filosofias de vida, tradições e instituições religiosas podem influenciar diferentes campos da esfera pública (política, saúde, educação, economia). (p. 457)
}

Desse modo, pareceu-nos que há toda uma área de atuação possível para o licenciado em filosofia que estaria habilitado a propor o currículo para o ensino religioso, uma vez que a depender de seu repertório de formação na história da filosofia ele poderia vir a se dedicar a pensar as problemáticas apontadas pelas competências e habilidades acima e que podem ser mais uma frente de discussão para os filósofos engajados no ensino de filosofia, a saber, a sua atuação no ensino fundamental. 
Entendemos, portanto, que mesmo no ensino fundamental, a depender dos interesses e formações do professor de filosofia, este poderia pleitear espaço curricular para propor práticas que desenvolvem as competências e habilidades destacadas acima.

\section{Considerações finais}

O presente artigo reúne informações oriundas da legislação educacional para embasar o discurso de todos aqueles que almejam pleitear espaços legítimos à ampla atuação da filosofia na educação básica. O que se procurou fazer aqui foi despir-se dos medos de que perdemos a árdua batalha e de que novamente o ensino de filosofia foi retirado do currículo do ensino médio. O procedimento foi ler o próprio documento e ir recolhendo fragmentos que apontam para uma necessidade de filosofia.

Após as ressalvas feitas acerca da concepção de pedagogia das competências que há na legislação educacional brasileira e, em especial, na BNCC, fizemos uma extração de noções e conceitos presentes nas competências gerais e competências e habilidades das Ciências Humanas e Sociais Aplicadas. E nesse movimento percebemos que há uma ampla gama de exigências que são eminentemente filosóficas. Divididas em três grupos, (metodológicas, políticas e éticas), as competências da área exigem que as redes de ensino mantenham a disciplina filosofia com carga horária regular sob a pena de não estarem cumprindo as determinações legais, visto que sem esse espaço será impossível garantir a ampliação e aprofundamento da base conceitual e sistematização do raciocínio, preconizadas na Base (BNCC, 2018, p. 472).

Também apontamos aqui que as Orientações Curriculares Nacionais para as Ciências Humanas e suas Tecnologias (2006) continua um documento importante para complementar a BNCC, ao apresentar competências especificamente filosóficas e que podem ajudar a fundamentar a construção de itinerários formativos em Humanas nas redes estaduais e privadas. 
Ressaltando o ponto de que com o novo desenho do ensino médio, a luta e a defesa dos espaços da filosofia no currículo da educação básica se darão a cada definição de currículo estadual, a cada diretriz curricular nas redes privadas, a cada criação de livros didáticos para o PNLD. Acostumados a argumentar em defesa da presença da filosofia na educação básica, nós professores de filosofia precisaremos estar atentos e fortes para cada cenário, afinal, desde Aristóteles é necessário lembrar nossos pares que a humanidade não chega à sua excelência somente através de artes úteis e pragmáticas: "Todas as outras são, pois, mais necessárias do que ela, mas nenhuma se Ihe sobreleva em excelência". (Aristóteles, 1973, p. 215)

\section{Referências}

ARISTÓTELES, Metafísica. Tradução de Vicenzo Cocco. Abril cultural, São Paulo, 1973. (Coleção os pensadores).

BRASIL. Lei n 9.394, de 20 de dezembro de 1996. Estabelece as diretrizes e bases da educação nacional. Diário Oficial da União, Brasília, DF, 23 dez. 1996.

BRASIL. Conselho Nacional de Educação. Câmara da Educação Básica. Parecer 15/98; Resolução 03/98. Diretrizes Curriculares Nacionais para o Ensino Médio. Brasília, CNE/CEB, 1998.

BRASIL. Ministério da Educação. Parâmetros Curriculares Nacionais para o Ensino Médio. Brasília. MEC/SEMTEC, 1999.

BRASIL. Orientações Curriculares Nacionais. Ciências humanas e suas tecnologias/ Secretaria de Educação Básica. - Brasília: Ministério da Educação, Secretaria de Educação Básica, 2006.

BRASIL. Base Nacional Comum Curricular: Educaçao é a base - Ensino Médio. 2018. Disponível em: http://basenacionalcomum.mec.gov.br/images/BNCC_EI_EF_110518_versaofinal_sit e.pdf. Acesso em: 06/08/2021.

DELORS, Jacques et al. Educação, um tesouro a descobrir. Relatório para a UNESCO da comissão Internacional sobre Educação para o século XXI. Trad José Carlos Eufrazio. UNESCO/Edições ASA/Cortez, São Paulo, 1997 
LAVAL, Christian. A escola não é uma empresa, o neoliberalismo em ataque ao ensino público. Trad. Mariana Echalar, Boitempo, São Paulo, 2019.

NOGUEIRA, Renato. O tabu da filosofia. In: Filosofia (São Paulo), v. 1, p. 45, 2014.

PERRENOUD, Philippe. Construir as competências desde a escola. Trad. Bruno Charles Magne. Artmed editora, Porto Alegre, 1999.

SILVA, Monica Ribeiro da. A BNCC DA REFORMA DO ENSINO MÉDIO: O RESGATE DE UM EMPOEIRADO DISCURSO. Educação em Revista, Belo Horizonte, v.34, 2018.

TARDIF, J. Le transfer de comptétences analysé a traverslaformation de professionnels. In. MEIRIEU PH., DEVELAY M., DURAND C., e MARIANI Y. (orgs), Le concept de transfert de connaissance em formationinitiale et continue, Lyon, CRDP, p 31-46, 1996.

\section{(c) (i) (ㄱ) (2)}

This work is licensed under a Creative Commons Attribution-NonCommercial 4.0 International (CC BY-NC 4.0) 